\title{
Magnetotelluric investigations for imaging electrical structure of Garhwal Himalayan corridor, Uttarakhand, India
}

\author{
M Israil*, D K Tyagi, P K Gupta and Sri Niwas \\ Department of Earth Sciences, Indian Institute of Technology Roorkee, Roorkee 247 667, India. \\ *e-mail: mohdfes@iitr.ernet.in
}

\begin{abstract}
Magnetotelluric investigations have been carried out in the Garhwal Himalayan corridor to delineate the electrical structure of the crust along a profile extending from Indo-Gangetic Plain to Higher Himalayan region in Uttarakhand, India. The profile passing through major Himalayan thrusts: Himalayan Frontal Thrust (HFF), Main Boundary Thrust (MBT) and Main Central Thrust (MCT), is nearly perpendicular to the regional geological strike. Data processing and impedance analysis indicate that out of 44 stations MT data recorded, only 27 stations data show in general, the validity of $2 \mathrm{D}$ assumption. The average geoelectric strike, $\mathrm{N} 70^{\circ} \mathrm{W}$, was estimated for the profile using tensor decomposition. 2D smooth geoelectrical model has been presented, which provides the electrical image of the shallow and deeper crustal structure. The major features of the model are (i) a low resistivity $(<50 \Omega \mathrm{m})$, shallow feature interpreted as sediments of Siwalik and Indo-Gangetic Plain, (ii) highly resistive $(>1000 \Omega \mathrm{m})$ zone below the sediments at a depth of $6 \mathrm{~km}$, interpreted as the top surface of the Indian plate, (iii) a low resistivity $(<10 \Omega \mathrm{m})$ below the depth of $6 \mathrm{~km}$ near MCT zone coincides with the intense micro-seismic activity in the region. The zone is interpreted as the partial melting or fluid phase at mid crustal depth. Sensitivity test indicates that the major features of the geoelectrical model are relevant and desired by the MT data.
\end{abstract}

\section{Introduction}

The Himalayas originated as a result of continental collision tectonics and underthrusting of the Indian Plate beneath the Eurasian Plate. At least $1400 \mathrm{~km}$ of convergence has been accommodated by a combination of underthrusting of Indian lithosphere, crustal shortening, horizontal extrusion and lithospheric delamination (Molnar 1990). In this process the leading face of the upper brittle portion of the subducting Indian crust has been sliced and stacked up southwards to form the Himalayan mountain belt. The various thrusts are the elements of this geodynamical process. Seeber et al (1981) have postulated a gently dipping thrust (detachment surface) under the Indo-Gangetic plain coinciding with the upper surface of the subducting Indian lithosphere. The Main Himalayan Thrust (MHT) is interpreted as the top of the underthrusting Indian plate. The southernmost unit, the outer Himalaya, consists of $5-6 \mathrm{~km}$ thick Siwalik sediments, composing sandstones, conglomerates, clay and silt, which were deposited in brackish and freshwater environment. The location of Mohand is marked in the study area, whereas Ramnagar is located outside the study area (figure 1). The Siwalik system forms the low hills that rise in front of the Indo-Gangetic Plain (IGP). A series of reverse faults, Himalayan Frontal Fault (HFF), representing the youngest thrust zone, was activated during Pleistocene and it demarcates the tectonic 


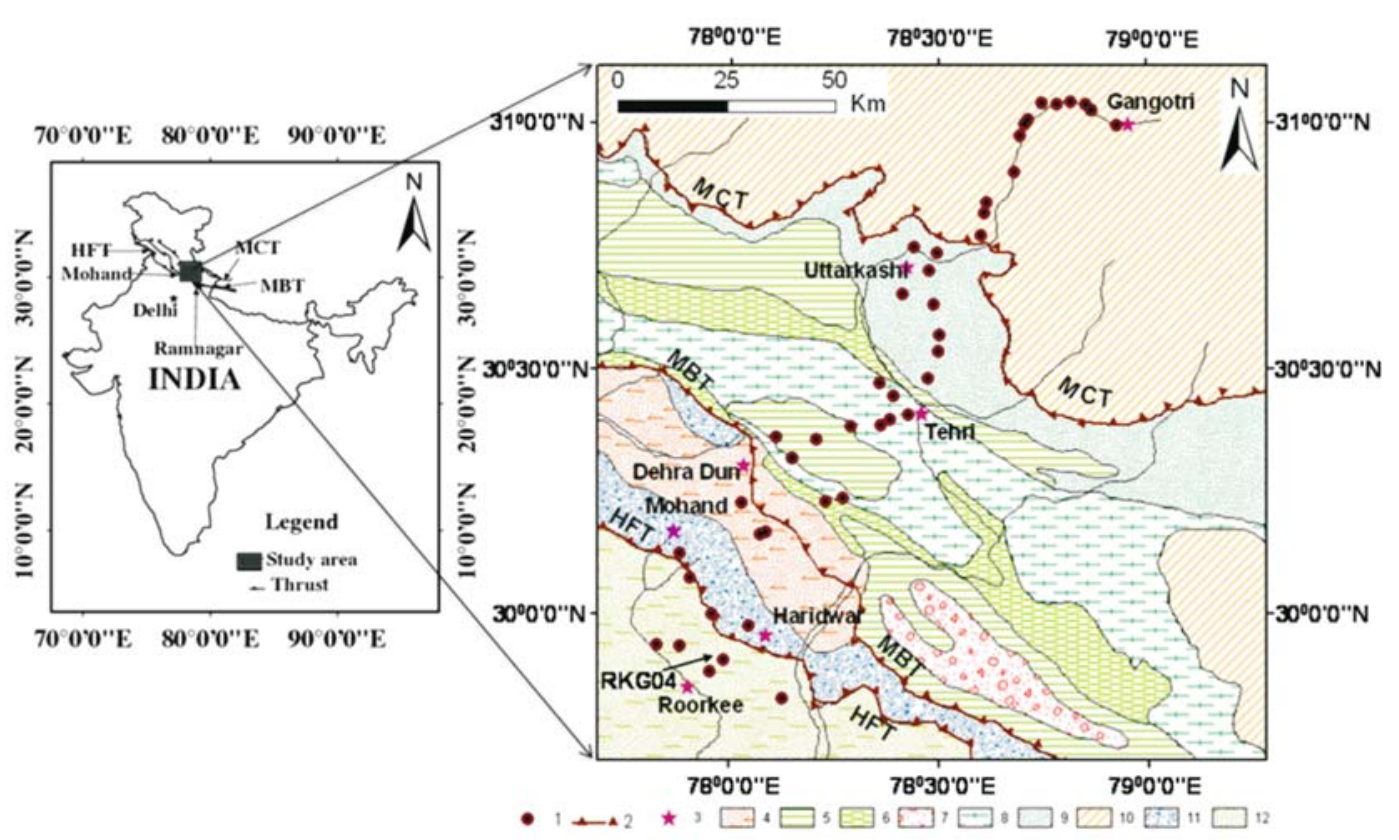

Figure 1. Location of the study area (geological map compiled from Virdi 1988; Sorkhabi et al 1999; Kumar et al 2002). (1) MT sites; (2) Thrust; (3) Cities; (4) Dehra Dun Re-entrant; (5) Blaini-Infrakrol-Krol; (6) DaMTha; (7) Garwhal Nappe; (8) Jaunsar-Simla (undifferentiated); (9) Sunder Nagar-Berinag Groups; (10) Undifferentiated metamorphics; (11) Undifferentiated tertiaries; (12) Piedmont zone. MT data collected in the Indo-Gangetic Plain, Siwalik, Lesser and Higher Himalayan regions in Garhwal Himalaya.

boundary between Siwalik and the IGP (Valdiya 2003). The Siwalik domain having an average elevation of about $600 \mathrm{~m}$ comprises the folded, faulted and tilted mollasse of the Miocene and younger age. They show evidence of recent tectonic movements (Valdiya 2003). The northern boundary of this domain is defined by the Main Boundary Thrust (MBT) which hades northwards at $30^{\circ}-40^{\circ}$. The Lesser Himalayan domain, which follows on the north, has an average elevation of $2500 \mathrm{~m}$ with a slight gradient towards the north. The rocks are considerably folded and fractured (LeFort 1975). The Main Central Thrust (MCT) hading northwards at $40^{\circ}-50^{\circ}$ separates the Lesser Himalaya domain from the Great Himalaya domain on the north. The Great Himalaya domain is composed of high-grade metamorphic rocks and has an average elevation of $4500 \mathrm{~m}$. The major Himalayan thrusts are broadly parallel to each other, steeper near surface and become shallow with the depth until they merge with the detachment surface. The main tectonic elements of Garhwal Himalayan region have an average strike of NW-SE (Seeber et al 1981; Khattri 1992).

Vozoff (1984) conducted theoretical modeling for the possible magnetotelluric (MT) traverse and suggested a need of detailed field MT investigation in the Himalaya region. Magneto-variation (MV) studies (Lilley et al 1981; Arora et al 1982), carried out over a rectangular array of 24 stations in the Siwalik Himalayan region, indicated the presence of a conductive anomaly, which they interpreted as an extension of the Aravallis and referred to it as Trans Himalayan conductor. Subsequently, MT investigations were carried out by Gupta et al (1994) in the Siwalik region over $150 \mathrm{~km}$ long Mohand-Ramnagar profile to determine the thickness of Siwalik sediments. They recorded MT data in the frequency range $0.01-100 \mathrm{~Hz}$ using short period MT system and estimated geoelectric strike of $\mathrm{N} 80^{\circ} \mathrm{W}$ on the basis of simple rotation of impedance tensor. Using 1D inversion of MT data they have delineated resistive basement below Lower Siwalik at a depth from $5-8 \mathrm{~km}$. Subsequently various MT investigations in the Himalayan region determine the electrical structure of the crust and its possible relationship to the geological structure and active tectonics (Chen et al 1996; Park and Mackie 1997 and Gokarn et al 2002). MT studies in central Nepal Himalaya have indicated that the conductive anomaly in the Higher Himalayan region is located in the zone where a large earthquake is expected to nucleate (Lemonnier et al 1999). Significant conducting zone with $5-60 \Omega \mathrm{m}$ and of thickness $1-1.5 \mathrm{~km}$ was delineated in eastern Himalaya by Bai and Meju 2003. Unsworth et al (2005) discussed the crustal rheology of the Himalaya derived from magnetotelluric data. The low resistivity zones were interpreted as a partially molten layer in the southern margin of Tibet plateau. The low resistivity zones at mid-crustal depth also appeared as bright spots 
Table 1. Various bands recorded and created by digital filter along with corresponding sampling interval and frequency range.

\begin{tabular}{llll}
\hline $\begin{array}{l}\text { Band } \\
\text { name }\end{array}$ & $\begin{array}{c}\text { Sampling } \\
\text { frequency/period }\end{array}$ & $\begin{array}{l}\text { Frequency/ } \\
\text { period range }\end{array}$ & \multicolumn{1}{c}{ Recording length } \\
\hline HF & $40960 \mathrm{~Hz}$ & $20000-500 \mathrm{~Hz}$ & $7 \mathrm{~s}$ \\
LF1 & $4096 \mathrm{~Hz}$ & $1000-10 \mathrm{~Hz}$ & $300-600 \mathrm{~s}$ \\
Free & $1024 \mathrm{~Hz}$ & $480-5 \mathrm{~Hz}$ & $600-900 \mathrm{~s}$ \\
LF2 & $64 \mathrm{~Hz}$ & $30-1 \mathrm{~Hz}$ & $6-12 \mathrm{~h}$ \\
LF3 & $2 \mathrm{~Hz}$ & $0.9 \mathrm{~Hz}$ to $10 \mathrm{~s}$ & $48-100 \mathrm{~h}$ \\
LF4 & $2 \mathrm{~s}$ & $5-100 \mathrm{~s}$ & Created by digital filter \\
LF5 & $8 \mathrm{~s}$ & $20-4000 \mathrm{~s}$ & Created by digital filter \\
\hline
\end{tabular}

in the seismic survey, related to the presence of the fluid phase. Low resistivity crust in combination with increased heat flow, is considered as an indicator of partial melting. Only a few transects in Himalayan collision zone have been studied using magnetotelluric technique and there is a need for detailed broad band MT investigations to delineate electrical structure along the various segment passes through the sub Himalayan, Lesser and Higher Himalayan region. Keeping this in view, the present MT study was initiated in the Garhwal Himalayan corridor.

A broad band MT survey was conducted in the Garhwal Himalayan corridor passing through the major Himalayan thrusts. During 2004-06, data were recorded in the frequency band $1000-$ $0.001 \mathrm{~Hz}$ along the $300 \mathrm{~km}$ (along road) profile, extending from Himalayan Foothill region to Higher Himalayan region. The system used in this survey was Metronix, MT system, with ADU-06 data logger, MFS-06 induction coil magnetometer and EFP-06 electrodes. The paper presents the results of field survey and data analysis and the electrical structure of the crust along the profile inferred from the $2 \mathrm{D}$ smooth inversion.

\section{Field survey and data analysis}

The locations of the 44 stations are shown in figure 1, along with a geological base map compiled from Virdi (1988); Sorkhabi et al (1999) and Kumar et al (2002). The profile extends from Roorkee to Gangotri and it passes through major Himalayan thrust zones and is approximately perpendicular to the regional geological strike. In order to record the desired frequency range, the time series at each site was recorded in five different bands representing different frequency intervals. The detailed description of the bands recorded and created by digital filtering along with corresponding frequency interval are given in table 1.

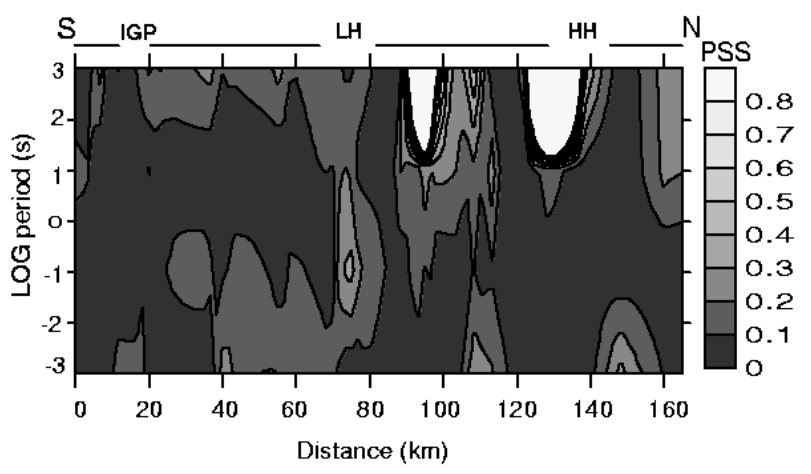

Figure 2. Plot of Bahr's phase sensitive skew for 27 sites.

The Himalayan terrain is tough and generally inaccessible. It is very difficult to find a good electrically noise free site. There are several hydropower projects in the area and some are in progress. One of the major hydropower projects "Tehri Dam" falls in the study area. The profile passes through hills and valley type topography with elevation varying from $230 \mathrm{~m}$ at Roorkee to $2980 \mathrm{~m}$ at Gangotri. The site number increasing from Roorkee to Gangotri is defined with station code RKG (e.g., first site near Roorkee, RKG01, and last site at Gangotri, RKG44). Due to various developmental activities and limited accessibility in the terrain, it was not possible to occupy the planned sites keeping constant site interval. Further, several sites were in the deep forest, inhabited by wild animals which led to some operational hazards. For example, at one site the electric cables were cut into pieces by animals. This led to forced repetition of the data. Based on geological inputs, the entire profile length is divided into three segments: IndoGangetic Plain (IGP), Lesser Himalaya (LH) and Higher Himalaya $(\mathrm{HH})$ region.

The recorded time domain data were transformed to the frequency domain impedance tensor using magnetotelluric processing (MAPROS) code (Friedrichs 2003). The measured impedance tensor is distorted by local small scale structure and may also have $3 \mathrm{D}$ effects. The tensor analysis is 

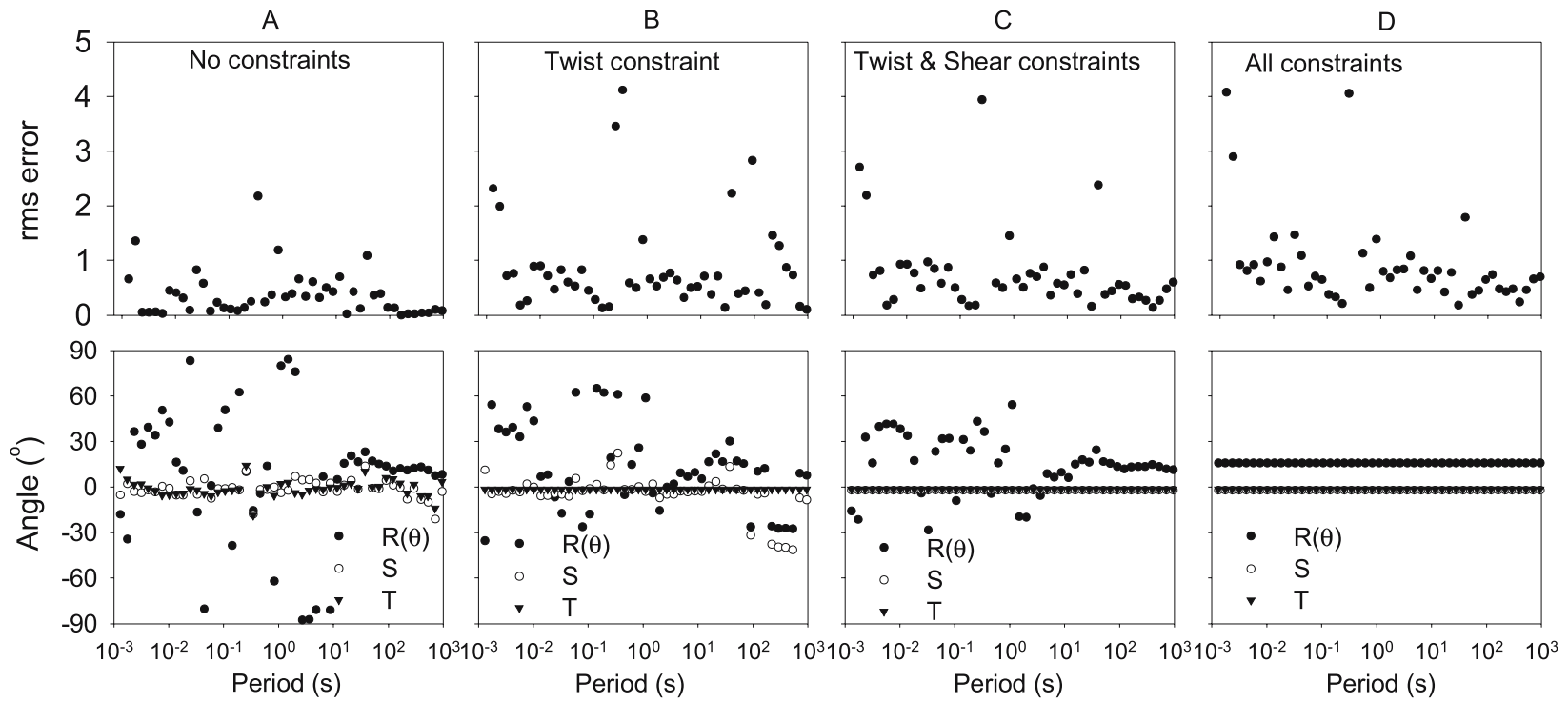

Twist $=-1.40$, Shear $=-2.0$, Strike $=16$, Avg rms error $=1.10$
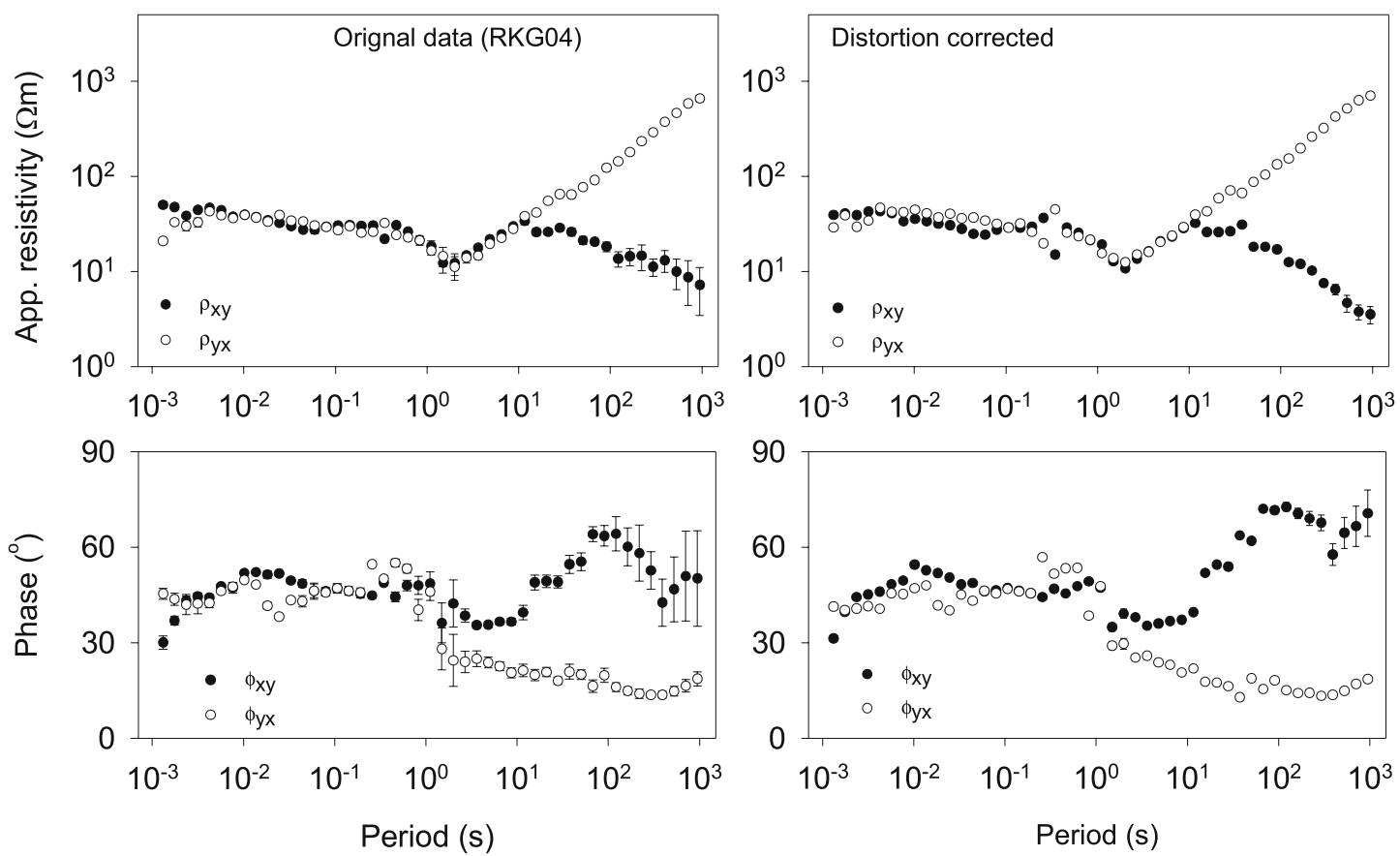

Figure 3. Single-site-single-frequency (SSSF) Groom-Bailey impedance decomposition of a site from Indo-Gangetic Plain to estimate the strike angle and distortion parameters (shear and twist).

therefore performed to determine intrinsic dimensionality and directionality of the geological structure with respect to the geographical coordinate system. Impedance tensor decomposition is a common methodology for studying impedance distortion. Various workers (Swift 1967; Larsen 1977; Bahr 1988, 1991; Groom and Bailey 1989; Groom et al 1993; Chave and Smith 1994) have introduced different impedance analysis technique. Bahr's Phase Sensitive skew (Bahr 1988) for all frequencies $(1000$ to $0.001 \mathrm{~Hz})$ is plotted in figure 2, which yields first impression about the dimensionality of the data. Figure 2 shows that the skew is less than 0.3 , in Indo-Gangetic Plain and Lesser Himalayan region indicating the validity of $2 \mathrm{D}$ assumption for the data. However, in Higher Himalayan region high skew $(>0.3)$ indicates a strong $3 \mathrm{D}$ effect in data. For the detailed analysis we have used Groom and Bailey (1989) decomposition, as implemented by McNeice and Jones (2001) strike code, to parameterize the distortion and to determine regional 2D impedance tensor and geoelectric strike direction from the measured impedance tensor. 


\section{Impedance tensor decomposition}

Groom and Bailey (1989) tensor decomposition models the observed impedance tensor $\left(Z_{\mathrm{obs}}\right)$ in terms of distortion parameters twist $(T)$, shear $(S)$ angles and regional 2D impedance tensor $\left(Z_{2 \mathrm{D}}\right)$ as follows,

$$
Z_{\mathrm{obs}}=R(\theta) T S Z_{2 \mathrm{D}} R^{T}(\theta)
$$

where $R(\theta)$ is a rotation matrix with angle $\theta$, as geoelectric strike direction. Physical basis of equation (1) is given by Groom and Bahr (1992). This factorization allows a separation of determinable distortions in terms of twist and shear angles from the observed impedance tensor. The limiting values of twist and shear angles is $\left|45^{\circ}\right|$. The distortion parameters twist $(T)$, shear $(S)$, the geoelectric strike and the regional impedance tensor $\left(Z_{2 \mathrm{D}}\right)$ are estimated using a least square method by fitting the observed impedance tensor with the decomposition model.

A detailed analysis has been done, to obtain consistent estimates of the geoelectric strike direction, using 'strike' code, in single-site singlefrequency (SSSF), single-site multi-frequency (SSMF) and multi-site multi-frequency (MSMF) modes (McNeice and Jones 2001).

In SSSF mode frequency dependent estimate of decomposition parameters is iteratively constrained to their respective stable values. The unconstrained decomposition at individual frequency revealed that the twist has stable value at most frequencies and sites, and at some sites shear also has stable value. Twist and shear were then constrained to their stable values and the decomposition procedure was repeated with only the unconstrained strike. Step by step implementation of decomposition in SSSF mode, to estimate the geoelectric strike angle is shown in figure 3 for a site located in Indo-Gangetic Plain.

It was observed that the twist values in three profile segments: the IGP, LH and HH vary in the ranges $\left(-2^{\circ}\right.$ to $\left.4^{\circ}\right),\left(-20^{\circ}\right.$ to $\left.20^{\circ}\right),\left(-3^{\circ}\right.$ to $\left.38^{\circ}\right)$. Similarly, the shear values vary in the ranges $\left(-2^{\circ}\right.$ to $\left.18^{\circ}\right),\left(-29^{\circ}\right.$ to $\left.34^{\circ}\right),\left(-15^{\circ}\right.$ to $\left.39^{\circ}\right)$. The numerical value of decomposition parameters, shear and twist, quantify the amount of galvanic distortion in the data and indicate the validity of $2 \mathrm{D}$ assumption for inversion. Table 2 shows the distortion parameters, shear and twist at each site obtained from SSSF mode. Based on the numerical values of distortion parameters, the individual site is characterized as, with small distortion (small shear and twist), mixed distortion (intermediate shear and twist) and with large distortion (high shear and twist). The distortion parameter with magnitude greater than $45^{\circ}$ is not meaningful (Groom and Bailey 1989). It was generally observed that in Higher Himalayan region MT data are strongly distorted. The average strike estimated by SSSF decomposition method in three regions: IGP, $\mathrm{LH}$ and $\mathrm{HH}$ respectively are $\mathrm{N} 15^{\circ} \mathrm{E}, \mathrm{N} 23^{\circ} \mathrm{E}$ and $\mathrm{N} 21^{\circ} \mathrm{E}$, and with $90^{\circ}$ ambiguity, $\mathrm{N} 75^{\circ} \mathrm{W}, \mathrm{N} 67^{\circ} \mathrm{W}$ and $\mathrm{N} 69^{\circ} \mathrm{W}$. Garhwal Himalayan region has an average strike of NW-SE (Khattri 1992), this fact has been used to remove the $90^{\circ}$ ambiguity in estimated strike direction. This led to the acceptable geoelectrical strike in the three regions as $\mathrm{N} 75^{\circ} \mathrm{W}, \mathrm{N} 67^{\circ} \mathrm{W}$ and $\mathrm{N} 69^{\circ} \mathrm{W}$ respectively.

Next the 'strike' code was run in SSMF mode, in which each decomposition parameter is defined for one complete decade of frequencies. The entire frequency band (1000 to $0.001 \mathrm{~s}$ ) is divided into 6 decades. It has been observed that the strike is unstable in high frequency band (1000 to $1 \mathrm{~Hz})$ while it is fairly stable in low frequency band (1 to $0.001 \mathrm{~s}$ ). The rose diagram showing the geoelectric strike for all sites is given in figure 4 . The shear and twist analysis indicates that the data from IGP and LH regions are characterized by small distortions whereas large distortion in the data from $\mathrm{HH}$ region is observed.

MSMF mode of tensor decomposition was also implemented. The analysis has been done by fitting entire dataset for each region to consistent values of decomposition parameters. It led to geoelectric strikes for IGP, $\mathrm{LH}$ and $\mathrm{HH}$ regions as $\mathrm{N} 79^{\circ} \mathrm{W}$, $\mathrm{N} 66^{\circ} \mathrm{W}$ and $\mathrm{N} 64^{\circ} \mathrm{W}$ respectively. The decomposition analysis suggests an average strike direction of $\mathrm{N} 70^{\circ} \mathrm{W}$ for the entire profile. Finally, the measured responses are rotated in the estimated strike direction to obtain TE and TM response for inversion.

Gupta et al (1994) had earlier estimated the geoelectric strike in IGP and $\mathrm{LH}$ region as $\mathrm{N} 80^{\circ} \mathrm{W}$ on the basis of simple rotation of impedance tensor measured in the frequency range of $0.01-100 \mathrm{~Hz}$. Lemonnier et al (1999) have done an MT survey in central Nepal of the Himalayan region, where the regional strike $\mathrm{N} 70^{\circ} \mathrm{W}$ was estimated. The geoelectric strike estimated in the present analysis is consistent with the geological strike in Garhwal Himalayan region and is also consistent with the value estimated by other magnetotelluric workers.

\section{2D Inversion of MT data}

Smooth inversion finds the smoothest model whose response fits the observed data. The misfit between the observed apparent resistivity $\left(\rho^{\circ}\right)$ and phase $\left(\psi^{o}\right)$ and the corresponding computed apparent resistivity $\left(\rho^{c}\right)$ and phase $\left(\psi^{c}\right)$ is given by the 
Table 2. Decomposition parameters (shear and twist) and geoelectric strike estimated using 'strike' code in single site single frequency (SSSF) mode.

\begin{tabular}{|c|c|c|c|c|c|c|}
\hline Site & Station & Period (s) & Twist $\left({ }^{\circ}\right)$ & Shear $\left(^{\circ}\right)$ & Strike $\left(^{\circ}\right)$ & $\begin{array}{l}\text { Average rms } \\
\text { error }\end{array}$ \\
\hline 1 & RKG01 & $0.001-1000$ & -0.80 & -1.30 & N13E & 1.00 \\
\hline 2 & RKG02 & $0.001-1000$ & -0.40 & -1.15 & N14E & 1.10 \\
\hline 3 & RKG04 & $0.001-1000$ & -1.40 & -2.00 & N16E & 1.10 \\
\hline 4 & RKG05 & $0.001-1000$ & 1.40 & -1.20 & $\mathrm{~N} 18 \mathrm{E}$ & 0.70 \\
\hline 5 & RKG06 & $0.001-1000$ & -0.40 & -0.80 & N09E & 0.50 \\
\hline 6 & RKG07 & $0.001-1000$ & -2.00 & 3.00 & $\mathrm{~N} 12 \mathrm{E}$ & 1.00 \\
\hline 7 & RKG08 & $0.001-1000$ & 3.90 & 1.70 & N18E & 1.10 \\
\hline 8 & RKG09 & $0.001-1000$ & -2.00 & 11.80 & N15E & 2.70 \\
\hline 9 & RKG10 & $0.001-1000$ & -1.50 & 2.00 & N17E & 1.10 \\
\hline 10 & RKG11 & $0.001-1000$ & -0.60 & 1.30 & $\mathrm{~N} 16 \mathrm{E}$ & 1.10 \\
\hline 11 & RKG12 & $0.001-1000$ & -0.15 & -1.25 & N19E & 1.60 \\
\hline 12 & RKG15 & $0.001-1000$ & 4.00 & 6.80 & $\mathrm{~N} 21 \mathrm{E}$ & 2.40 \\
\hline 13 & RKG16 & $0.001-1000$ & -4.90 & 13.20 & N19E & 1.80 \\
\hline 14 & RKG18 & $0.001-1000$ & 4.90 & 16.70 & $\mathrm{~N} 21 \mathrm{E}$ & 3.00 \\
\hline 15 & RKG19 & $0.001-1000$ & -6.20 & 30.00 & N16E & 3.70 \\
\hline 16 & RKG20 & $0.001-1000$ & -1.70 & 33.70 & $\mathrm{~N} 27 \mathrm{E}$ & 1.30 \\
\hline 17 & RKG24 & $0.001-1000$ & -19.80 & -29.40 & N37E & 0.60 \\
\hline 18 & RKG25 & $0.001-1000$ & -10.00 & -12.00 & $\mathrm{~N} 22 \mathrm{~W}$ & 2.80 \\
\hline 19 & RKG26 & $0.001-1000$ & 19.50 & -28.40 & N16E & 1.10 \\
\hline 20 & RKG27 & $0.001-1000$ & 2.30 & -11.70 & $\mathrm{~N} 22 \mathrm{E}$ & 1.50 \\
\hline 21 & RKG29 & $0.001-1000$ & 2.30 & 16.00 & N63W & 1.70 \\
\hline 22 & RKG31 & $0.001-1000$ & 4.30 & -27.00 & $\mathrm{~N} 28 \mathrm{E}$ & 1.40 \\
\hline 23 & RKG32 & $0.001-1000$ & -2.60 & 1.50 & $\mathrm{~N} 15 \mathrm{E}$ & 4.20 \\
\hline 24 & RKG34 & $0.001-1000$ & 38.30 & 38.40 & $\mathrm{~N} 23 \mathrm{E}$ & 0.50 \\
\hline 25 & RKG35 & $0.001-1000$ & 18.70 & 11.60 & $\mathrm{~N} 22 \mathrm{E}$ & 3.00 \\
\hline 26 & RKG37 & $0.001-1000$ & 22.00 & 35.20 & N67W & 2.10 \\
\hline 27 & RKG44 & $0.001-1000$ & -3.10 & -15.20 & $\mathrm{~N} 22 \mathrm{E}$ & 1.40 \\
\hline
\end{tabular}

estimated root mean square (rms) error, $\varepsilon$, defined as (Xiao 2004),

$$
\varepsilon=\sqrt{\frac{1}{2 N M} \sum_{j=1}^{M} \sum_{i=1}^{N}\left[\left(\frac{\rho_{i j}^{o}-\rho_{i j}^{c}}{e_{\rho i j}}\right)^{2}+\left(\frac{\psi_{i j}^{o}-\psi_{i j}^{c}}{e_{\psi i j}}\right)^{2}\right]} .
$$

Here, suffices $i$ and $j$ specify the $i$ th site $j$ th frequency, superscripts $o$ and $c$ imply observation and corresponding computed response. $N$ is the number of sites, $M$ is the number of frequencies at each site, $e_{\rho}$ and $e_{\Psi}$ are the standard errors associated with the apparent resistivity and phase at each data point, respectively.

Instead of using variable individual data point errors, we have used error floors in apparent resistivity $\rho$ and in phase $\psi$, which provide a more uniform fit to the observed data. The error floor for a dataset is defined as the average error level in the data.
Inversion has been done without correcting the data for static shift. Any static shift in the data will appear as an additional error factor in the apparent resistivity. As the phase is not affected by static shift, error floor in phase is kept lower than the error floor in apparent resistivity. To accommodate any static shift, error floor of magnitude $20 \%$ in apparent resistivity and $10 \%$ in phase is used. An rms misfit significantly larger than unity indicates that the inversion is incapable of fitting the MT data. It either implies that the noise in the data is larger than the defined error floor or that a three-dimensional effect is present in the data. A misfit significantly less than unity indicates that either the errors are too small or that the data are being over fitted. In the latter case, the resistivity model usually is very rough. Generally, an rms misfit between 1 and 2 is an optimal choice.

The inverse problem is solved in the sense of Tikhonov and Arsenin (1977), where an objective function, $\phi$, defined below, is minimized, 


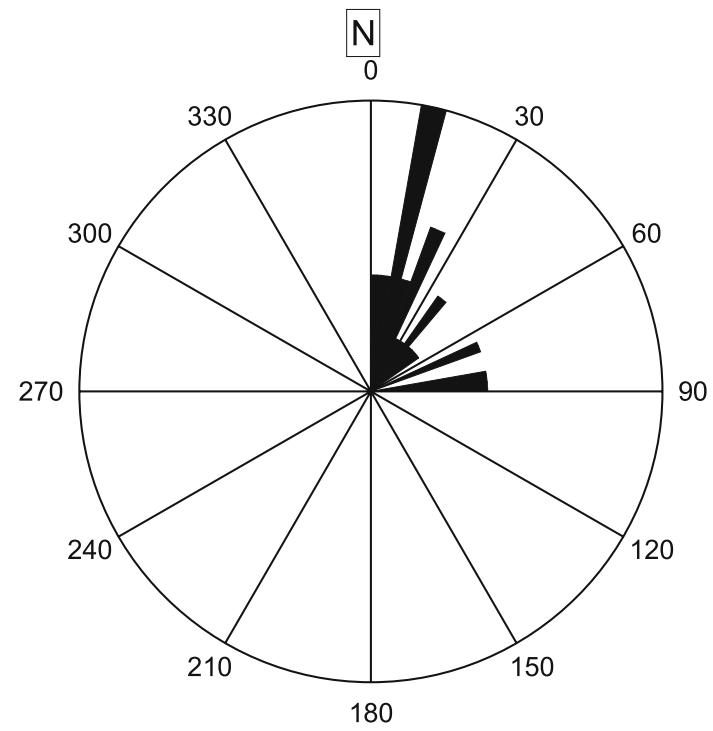

Figure 4. Rose diagram showing strike estimated from single-site-multi frequency (SSMF) mode.

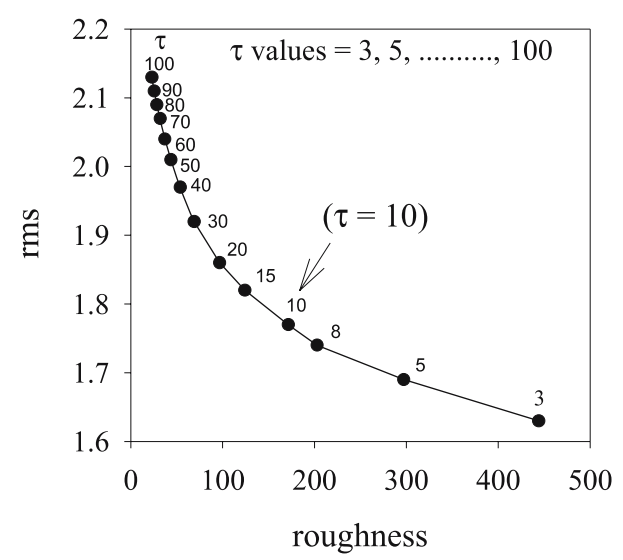

Figure 5. Trade-off between root mean square (rms) and model roughness, resulting in a typical $L$-curve. An optimal choice of parameter $(\tau)$ is 10 .

$$
\begin{aligned}
\phi(m)= & (d-F[m])^{T} V^{-1}(d-F[m]) \\
& +\tau m^{T} L^{T} L m .
\end{aligned}
$$

Here $d$ is the observed data vector, $F$ is the forward modeling operator, $m$ is the unknown model vector, $V$ is the positive definite covariance matrix of the data errors, $\tau$ is regularization parameter, $L$ is linear regularization operator. In equation (3), the first term measures the data misfit and the second term, the model smoothness. The trade-off between data misfit and model smoothness is controlled by the regularization parameter $\tau$. We have used Rodi and Mackie (2001) code as implemented in WinGlink software package for $2 \mathrm{D}$ smooth inversion of MT data. The para- meter $\tau$ is not automatically determined, but found through several inversions with different values of $\tau$. With increasing $\tau$ both data misfit and smoothness increase. An optimum smoothness parameter, $\tau$, is obtained by the trade-off between the smoothness of the model and rms misfit. Large values cause a smoother model at the expense of a worse data fit. The smoothness $(\tau), 10$, is obtained from the L-curve (Hansen 1998; Patro et al 2005a, 2005b) plotted in figure 5, between model roughness and rms error for the present dataset. We have used Laplacian operator as smoothing operator, $L$, which is defined as

$$
L=\frac{\alpha \partial^{2}}{\partial y^{2}}+\frac{\beta \partial^{2}}{\partial z^{2}} .
$$

Here $\alpha$ and $\beta$ are the weights for horizontal and vertical smoothness.

An increase of the weight $\alpha$, increases the horizontal smoothness of the model and an increase of $\beta$, increases the vertical smoothness of the model. By systematic trials, an optimal value for the weights $\alpha$ and $\beta$ is estimated as 3 and 1 respectively.

Theoretical studies demonstrate varying sensitivity of MT data for different geo-electrical structures. TE-mode impedance is more sensitive to the buried deep lithospheric conductor whereas TM-mode impedance is poorly sensitive to deep conductive structure. On the contrary, TM-mode impedance is more sensitive to the lithospheric resistance than is the TE-mode one. It has also been experienced that 1D inversion of TE-mode apparent resistivity curve is less affected by lateral inhomogeneities. In addition the TM-mode apparent resistivity curve changes shape in the presence of lateral discontinuity. Sensitivity of TE and TM mode responses to the electrical structure has been studied in detail by Berdichevsky et al (1998).

Keeping in view the different sensitivities of TE and TM mode responses to the geoelectrical structure, we have carried out inversion in three stages sequentially to arrive at a consistent geoelectrical model. Inversion has been initiated with a $100 \Omega \mathrm{m}$ homogeneous half space initial model with only TE mode data. The inverted model obtained from TE mode data is used as an initial model for inversion of TM mode data. The inverted model thus obtained from TM mode data inversion has been used as an initial model for the inversion of joint TE and TM responses. Thus, the final model incorporates the important features of both TE and TM responses. For consistency or nonuniqueness checks, the inversion experiments were repeated with four different half-space $(30,100,300$ and $500 \Omega \mathrm{m}$ ) initial models. Further, initial guess 

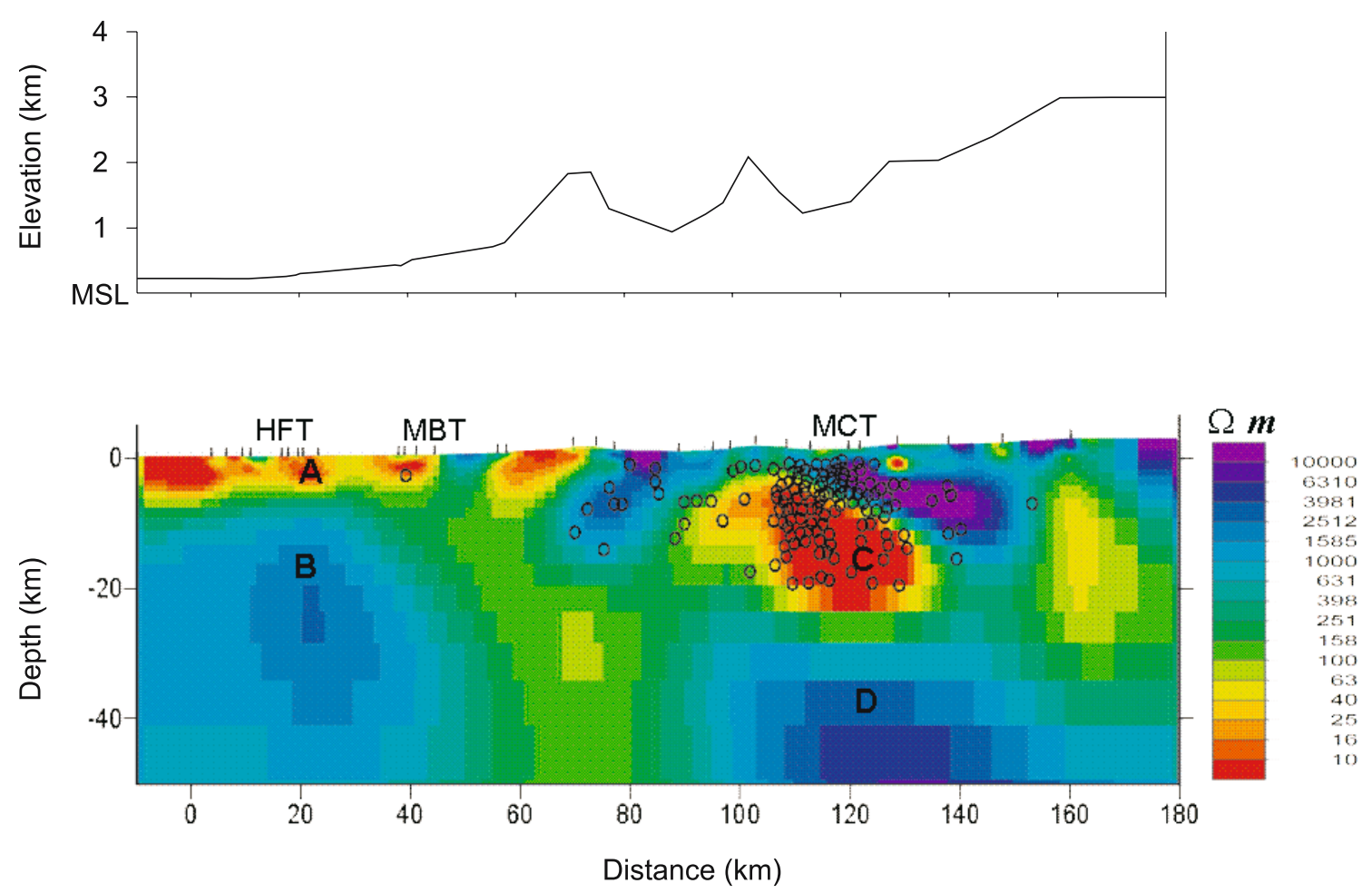

Figure 6. 2D resistivity models of Roorkee-Gangotri profile in Garhwal Himalaya corridor with (i) elevation profile on the top, (ii) 2D smooth geoelectric model obtained from the joint inversion of TE, TM responses (iii) the local seismicity (hypocenters) locations plotted as circles in the model, (iv) locations of $27 \mathrm{MT}$ sites indicated by vertical bar, (v) the major Himalayan thrusts (HFT, MBT, MCT).

model based on the experience of 1D inversion, were also tried for $2 \mathrm{D}$ inversion. The broad features of these models match except for a small degree of variations.

Finally, the main results are given in figure 6 which presents

- 2D smooth geoelectric model obtained from the joint inversion of TE and TM responses,

- the local seismicity (hypocenters) plotted as circle in the electrical model,

- elevation profile,

- locations of $27 \mathrm{MT}$ sites indicated by vertical bar,

- the major Himalayan thrusts.

The initial model for this case was constructed from the sequential inversion of individual TE and TM mode data. The observed and calculated response pseudo-sections are shown in figure 7 ( $\mathrm{a}$ and $\mathrm{b}$ ) for TE and TM modes respectively. Fitting of the TE and TM mode responses for the representative sites in three zones (IGP: RKG02, 5 and 8; LH: RKG12, 15, 18; and HH: RKG35, 37 and 44) are given in figure 8. The sites are numbered in increasing order from IGP to $\mathrm{HH}$. The root mean square (rms) errors at each site are also shown in figure 9 for only TE, only
TM, joint TE and TM mode inversions. The geoelectrical model is, in general, consistent with the tectonic model, indicating north dipping electrical features, however, due to resolution problem some features appear steeply dipping. The characters A, $\mathrm{B}, \mathrm{C}$ and $\mathrm{D}$ in figure 6 indicate the major electrical features of the model. The significance of each feature has been studied by carrying out a modeling experiment with and without the feature (Sarma et al 2004; Patro et al 2005a, 2005b). The electrical characteristics, the importance and possible geological inferences of each feature are given below.

\subsection{Feature A}

This is a shallow conductive structure $(<50 \Omega \mathrm{m})$ mainly confined in the southern part of the profile located in IGP and LH region. The conductive structure is extended to a depth of $6 \mathrm{~km}$. Geologically, the zone corresponds to the loose sediments, mollasse of the Miocene and younger age, transported from Higher Himalayan region. The shallow conductive zone is extending from site 1 to 12 , discontinued between sites 12 and 15 and it again appears as a small local conducting body between sites 15 and 18 . The resistive zone 


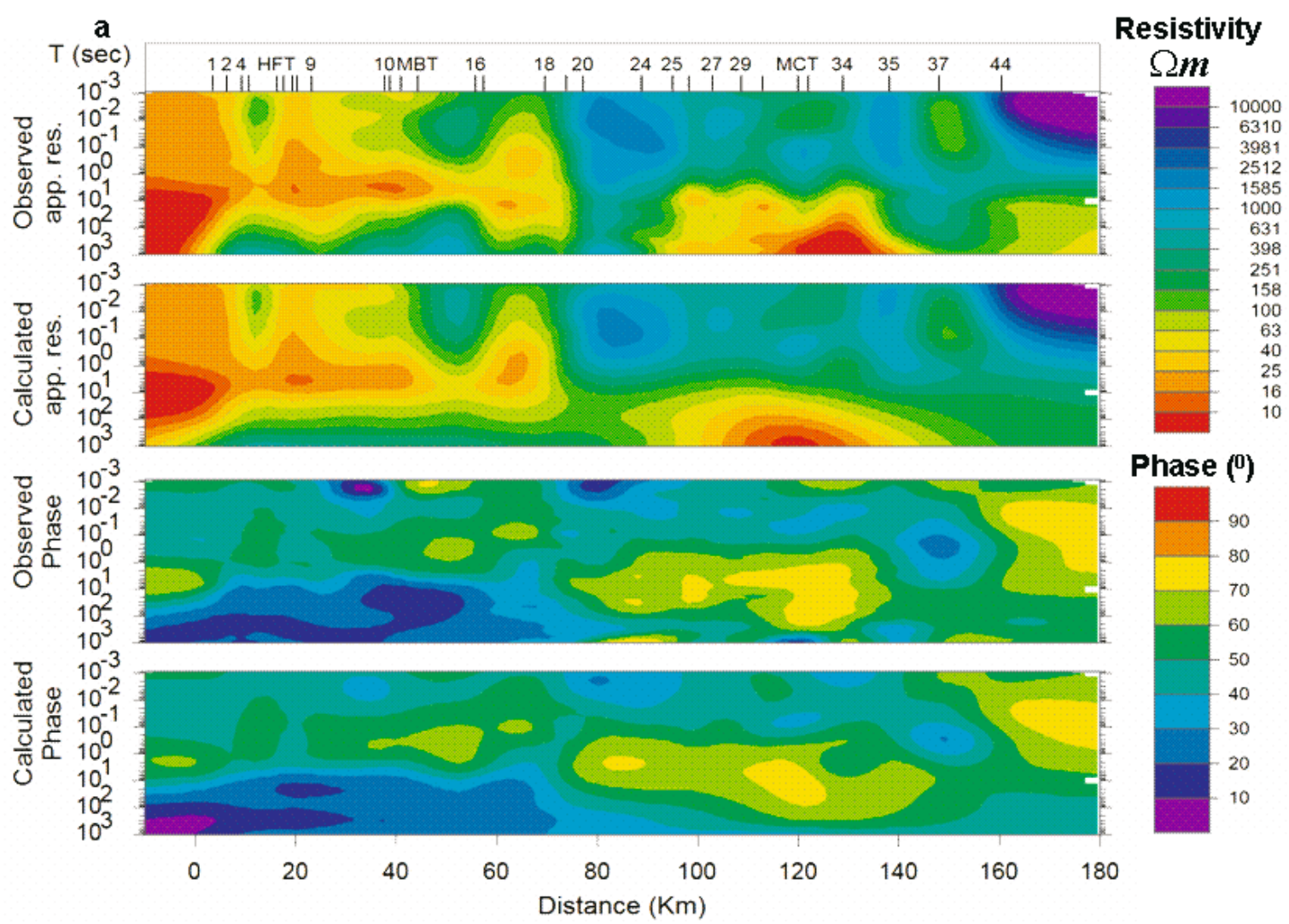

Figure 7(a). Pseudo-section plot of observed and calculated, TE-mode, apparent resistivity and phase responses.

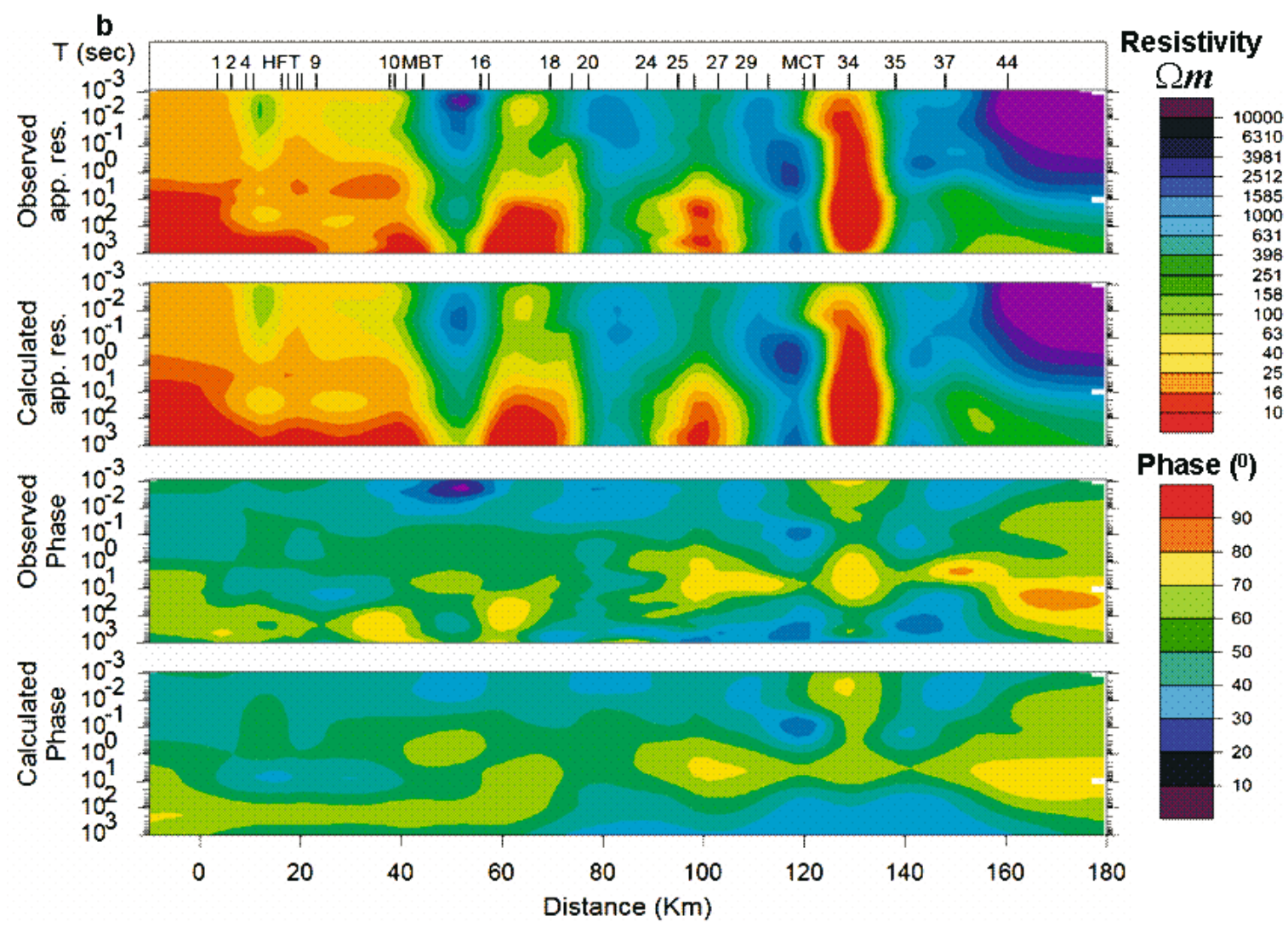

Figure 7(b). Pseudo-section plot of observed and calculated, TM-mode apparent resistivity and phase responses. 

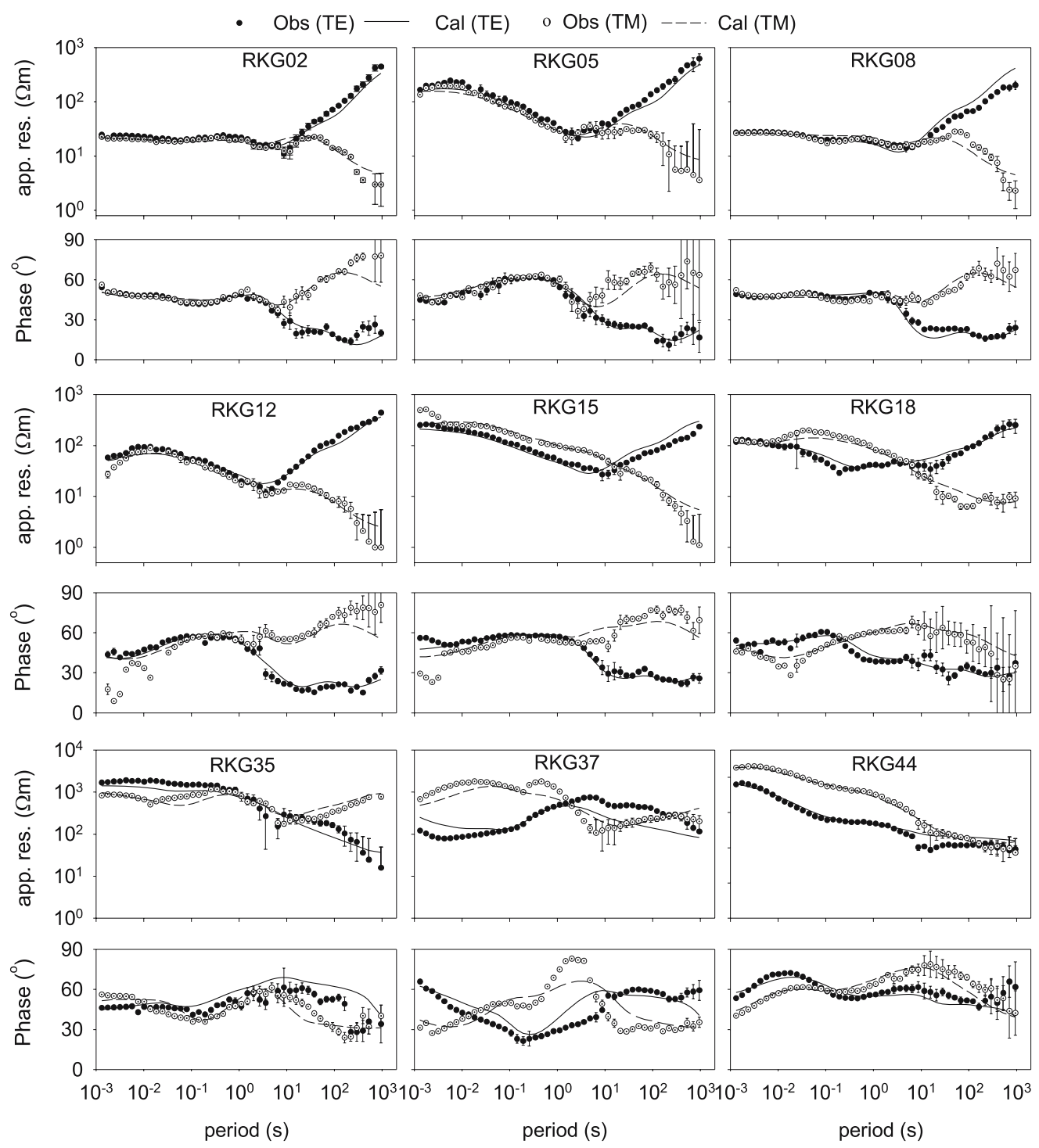

Figure 8. Fitting of observed and calculated apparent resistivity and phase responses in the three Himalayan regions, Indo-Gangetic Plain: RKG02, 5 and 8; Lesser Himalaya: RKG12, 15, 18; and Higher Himalaya: RKG35, 37 and 44.

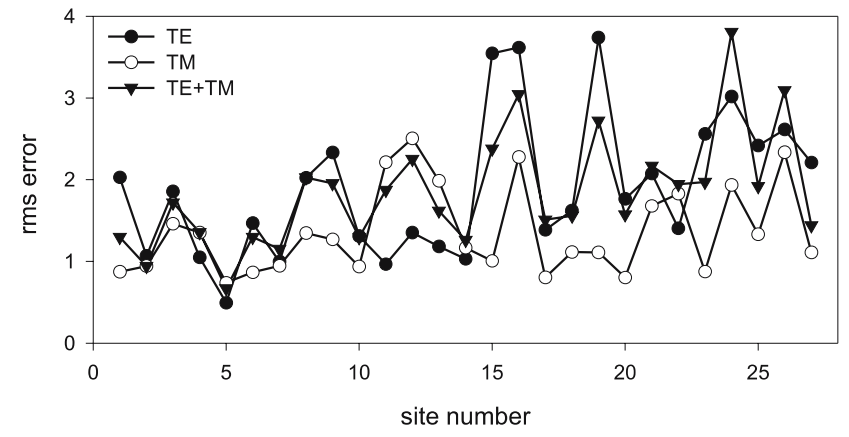

Figure 9. Root mean square (rms) error plotted for each site with iteration number for TE, TM and joint TE and TM mode inversion.

below it is interpreted as the top of Indian plate. The modeling experiment carried out with and without the feature "A" indicates that the model fitting is significantly distorted without the feature "A" for the sites lying on top of the feature. Therefore, we interpret it as an important electrical feature, which presents an electrical image of the sediments on the top surface of the Indian plate.

\subsection{Feature $B$}

This is a resistive formation with a resistivity larger than $1000 \Omega \mathrm{m}$ lying below the near surface conductive sediments. The resistivity of this feature reaches to a very high $(>6000 \Omega \mathrm{m})$ value at $25 \mathrm{~km}$ depth. The resistive formation is continued to a depth of $40 \mathrm{~km}$. Sensitivity test shows significant variation in the fitting of the responses without this feature. We interpret this feature as electrical image of the Indian crust. 


\subsection{Feature $C$}

This is a low resistivity $(<5 \Omega \mathrm{m})$ zone present below MCT. This zone is a typical example of low resistivity zone in mid crustal region invariably observed in the Himalayan region. The zone is extended laterally from Lesser to Higher Himalayan region mainly around MCT from MT stations, RKG 25 to 35 , and vertically from 6 to $25 \mathrm{~km}$ depth. This zone also appears to coincide with the location of hypocenters of local earthquake. Modeling studies show that the zone is significant for the MT data. Main Central Thrust (MCT) zone falls in high heat flow area, majority of hot springs are concentrated around this zone. GSI (1991) reported high heat flow $\left(130 \pm 30 \mathrm{~mW} / \mathrm{m}^{2}\right)$ and high temperature gradient $\left(60^{\circ} \pm 20^{\circ} \mathrm{C} / \mathrm{km}\right)$ in the MCT zone, whereas the foot hill Himalayan belts show low heat flow $\left(41 \pm 10 \mathrm{~mW} / \mathrm{m}^{2}\right)$ and low temperature gradient $\left(17^{\circ} \pm 5^{\circ} \mathrm{C} / \mathrm{km}\right)$. This suggests that the subsurface temperature is elevated in the MCT zone and the possible source of high heat flow is partial melt associated with fluids. This zone is indicated by a low resistivity value. The low resistivity zones are interpreted as a partially molten layer and the zones of high heat flow in MCT zone. The most likely conductive phase is fluids, since underthrusting of the Indian crust can ensure continuous recharge of the hanging wall by fluids released during dehydration reactions (Lemonnier et al 1999).

\subsection{Feature D}

This is a resistive feature underlying the low resistivity zone in mid crustal depth. Resistivity of this zone appears to be affected by the low resistivity zone on top of it. Modeling studies for the feature "D" indicate that there is no significant variation observed in the responses calculated with and without this feature. This may be due to low sensitivity of resistive structure beneath low resistivity layer. We interpret this feature as electrical image of the Indian crust.

The features discussed above are observed in all inverted geoelectrical models generated with various experiments with different initial guess models. However, these features do show a small degree of variations in different experiments.

\section{Conclusions}

Electrical structure has been studied on the basis of broad band MT data recorded along a profile in Garhwal Himalayan corridor. The model indicates a near surface shallow conductive zone in IndoGangetic plain and Lesser Himalayan region. It is discontinued and again appears as a small local conductive body. This conducting zone extending to a depth of $6 \mathrm{~km}$, represents sediments, mollasse of the Miocene and younger age. Under the shallow conductive zone the resistive layer at a depth of $6 \mathrm{~km}$ represents the top of Indian plate. The strong lateral electrical discontinuities are consistent with major Himalayan thrust zones, MBT and MCT. A conducting zone below $6 \mathrm{~km}$ depth in the vicinity of MCT extending up to $25 \mathrm{~km}$ under sites RKG25 to 35 is present. The zone is a typical example of low resistivity zone at mid crustal depth invariably present in Himalayan crust. The low resistivity zone appears to coincide with the intense micro-seismic activity in the region. The low resistivity may also be related to the zone of partial molten layer and increased heat flow in the MCT zone. This conductive zone is analogous to the similar conductive zone reported in the central Nepal-Himalaya profile (Lemonnier et al 1999). The conducting zone also appears to be related to the strain accumulation zone in Himalayan region for future earthquakes. Significance of various features in electrical model is defined by conducting sensitivity test for major features in the model.

The model present in this study is a result of 2D smooth inversion of MT data along the profile in Garhwal Himalaya, which can be improved by adding more data/information and by performing $3 \mathrm{D}$ inversion.

\section{Acknowledgements}

Authors are thankful to Prof. Alan G Jones, for providing the strike code for impedance decomposition. The present investigations were carried out with the financial support from Department of Science and Technology, Govt. of India.

\section{References}

Arora B R, Lilley F E M, Sloane M N, Singh B P, Srivastava B J and Prasad S N 1982 Geomagnetic induction and conductive structures in northwest India; Geophys. J. R. Astron. Soc. 69 459-475.

Bahr K 1988 Interpretation of the magnetotelluric impedance tensor: regional induction and local telluric distortion; J. Geophys. 62 119-127.

Bahr K 1991 Geological noise in magnetotelluric data: a classification of distortion types; Physics of the Earth and Planetary Interiors 66 24-38.

Bai D and Meju M A 2003 Deep structure of the LongingRuili fault underneath Ruili basin near the eastern Himalayan syntaxis: insights from magnetotelluric imaging; Tectonophys. 364 135-146.

Berdichevsky M N, Dmitriev V I and Pozdnjakova E E 1998 On two-dimensional interpretation of magnetotelluric soundings; Geophys. J. Int. 133 585-606. 
Chave A D and Smith J T 1994 On electric and magnetic galvanic distortion tensor decompositions; J. Geophys. Res. 99 4669-4682.

Chen L, Booker J R, Jones A G, Wu N, Unsworth M J, Wei W and Tan H 1996 Electrically conductive crust in southern Tibet from in depth MT surveying; Science $\mathbf{2 7 4}$ 1694-1696.

Friedrichs B 2003 MAPROS: magnetotelluric data processing software; Metronix GmbH, Braunschweig, Germany.

Gokarn S G, Rao C K and Gupta G 2002 Crustal structure in the Siwalik Himalayas using magnetotelluric studies; Earth Planets Space 54 19-30.

Groom R W and Bailey R C 1989 Decomposition of Magnetotelluric impedance tensors in the presence of local three-dimensional galvanic distortion; J. Geophys. Res. $941913-1925$

Groom R W, Kurtz R D, Jones A G and Boerner D E 1993 A quantitative methodology to extract regional magnetotelluric impedances and determine the dimension of conductive structure; Geophys. J. Int. 115 1095-1118.

Groom R W and Bahr K 1992 Correction for near surface effects: decomposition of the magnetotelluric impedance tensor and scaling corrections for regional resistivities: a tutorial; Surveys in Geophysics 13 341-379.

GSI 1991 Geothermal Atlas of India, Geological Survey of India, Special Publication, 19143.

Gupta G, Gokarn S G and Singh B P 1994 Thickness of the Siwalik Sediments in the Mohand-Ramnagar region using magnetotelluric studies; Physics of the Earth and Planetary Interiors 83 217-224.

Hansen, P C 1998 Rank deficient and discrete III-posed problems, numerical aspects of linear inversion; SIAM, Philadelphia.

Khattri K N 1992 Local seismic investigations in the Garhwal-Kumaun Himalaya; Geol. Soc. India Memoir 23 45-66.

Kumar R, Ghosh S K, Sangode S J and Thakur V C 2002 Manifestation of Intra - Foreland thrusting in the Neogene Himalaya foreland basin fill; J. Geol. Soc. India $\mathbf{5 9}$ $547-560$.

LeFort P 1975 Himalaya: the collided range. Present knowledge of the continental arc; Am. J. Sci. 275 7-44.

Larsen J C 1977 Removal of local surface conductivity effects from low frequency mantle response curves; Acta Geodaet., Geophys. Montanist. Acad. Sci. Hung. 12 183-186.

Lemonnier C, Marquis G, Perrier F, Avouac J P, Chitrakar G, Kafle B, Sapkota S, Gautam U, Tiwari D and Bano M 1999 Electrical structure of the Himalaya of central Nepal: high conductivity around the midcrustal ramp along the MHT; Geophys. Res. Let. 26 3261-3264.

Lilley F E M, Singh B, Arora B R, Srivastava B J, Prasad S N and Sloane M N 1981 A magnetometer array study in northwest India; Physics of the Earth and Planetary Interiors 25 232-240.
McNeice G W and Jones A G 2001 Multisite, multifrequency tenser decomposition of magnetotelluric data; Geophysics 66 158-173.

Molnar P 1990 A review of the seismicity and the rate of active underthrusting and deformation at the Himalaya; J. Himalayan Geol. 1(2) 131-154.

Park S K and Mackie R L 1997 Crustal structure at Naga Parbat, north Pakistan, from magnetotelluric soundings; Geophys. Res. Lett. 24 2415-2418.

Patro B P K, Brasse H, Sarma S V S and Harinarayana 2005a Electrical structure of the crust below the Deccan Flood Basalts (India), inferred from magnetotelluric soundings; Geophys. J. Int. 163 931-943.

Patro B P K, Harinarayana T, Sastry R S, Rao M, Manoj C, Naganjaneyulu K and Sarma S V S 2005b Electrical image of Narmada-Son lineament zone, central India from magnetotelluric; Physics of the Earth and Planetary Interiors 148 215-232.

Rodi W L and Mackie R L 2001 Nonlinear conjugate gradients algorithm for 2-D magnetotelluric inversion; Geophysics 66 174-187.

Sarma S V S, Patro B P K, Harinarayana T, Veeraswamy K, Sastry R S and Sarma M V C 2004 A magnetotelluric (MT) study across the Koyna seismic zone, Western India: evidence for block structure; Phys. Earth Planet. Inter. 142 23-36.

Seeber L, Armbruster J and Quittmeyer R C 1981 Seismicity and continental subduction in the Himalayan arc; In: Zagros-Hindukush-Himalaya Geodynamic Evolution (eds.) H Gupta and F Delany, American Geophysical Union, Geodynamics Series 3 215-242.

Sorkhabi R B, Stump E, Foland K and Jain A K 1999 Tectonic and cooling history of the Garhwal Higher Himalaya (Bhagirathi Valley): constraints from thermochronological data; Gondwana Research Group Memoir 6 217-235.

Swift C M J 1967 A magnetotelluric investigation of an electrical conductivity anomaly in the southwestern United State; Ph.D. Dissertation Geophysics Laboratory M I T, Cambridge.

Tikhonov A N and Arsenin V Y 1977 Solutions of ill-posed problems (V H Winston \& Sons.)

Unsworth M J, Jones A G, Wei W, Marquis G, Gokarn S G, Spratt J E and INDEPTH-MT Team 2005 Crustal rheology of the Himalaya and Southern Tibet inferred from magnetotelluric data; Nature 438 78-81.

Valdiya K S 2003 Reactivation of Himalayan Frontal Fault; Curr. Sci. 85 1031-1040.

Virdi N S 1988 Pre-Tertiary geotectonic events in the Himalaya; Z. Geol. Wiss, Berlin 16 571-585.

Vozoff K 1984 Model study for the proposed magnetotelluric (MT) traverse in north India; Tectonophys. 105 399-411.

Xiao W 2004 Magnetotelluric exploration in the rocky mountain foothills, Alberta; Master of Science dissertation, Department of Physics, University of Alberta, Edmonton, Alberta. 